\title{
Patología médica y embarazo. Trastornos respiratorios, urológicos, infecciosos y endocrinológicos
}

\section{Medical disorders and pregnancy. Respiratory, urologic, infectious and endocrinologic disorders}

\author{
M. Roche, A. F. Pérez Rodríguez, M.A. García Mutiloa, I. Martínez Montero
}

\section{RESUMEN}

El embarazo constituye una situación que modifica la fisiología de distintos órganos y sistemas. La aparición de enfermedades concomitantes o la presencia de las mismas previa a la gestación obliga al clínico a conocer estas modificaciones y su influencia en la enfermedad, así como la repercusión de la enfermedad y de los medios diagnósticos y terapéuticos en la mujer embarazada y en el feto. El objetivo de este trabajo es exponer de manera concisa las pautas de actuación más recomendadas ante gestantes que acuden al Servicio de Urgencias presentando síntomas de patología concomitante no específica del embarazo. Se presentan algunas de las patologías más frecuentes clasificadas por sistemas.

Palabras clave. Complicaciones obstétricas. Enfermedades respiratorias. Enfermedades urológicas. Enfermedades infecciosas. Enfermedades endocrinas.

\begin{abstract}
Pregnancy is a state that changes the physiology of various organs and systems. The occurrence of concomitant diseases, or their presence prior to pregnancy, requires an understanding of such changes and their influence on the disease, the impact of the disease and the diagnostic and therapeutic measures on pregnant women and on the foetus. The aim of this paper is to provide a concise outline of the course of action recommended in dealing with pregnant women who attend the emergency department presenting symptoms of non-specific morbidity of pregnancy. Some of the most frequent pathologies classified by systems are presented.
\end{abstract}

Key words. Pregnancy complications. Respiratory tract diseases. Urologic diseases. Infectious diseases. Endocrine diseases.
Servicio de Ginecología. Hospital Virgen del Camino. Pamplona

\section{Correspondencia:}

Milagros Roche Roche

Sección de Obstetricia y Ginecología

Hospital Virgen del Camino

Irunlarrea, 4

31009 Pamplona

Tfno. 948429526

E-mail: milagros.roche.roche@cfnavarra.es 


\section{INTRODUCCIÓN}

Las particularidades fisiológicas del embarazo, así como la susceptibilidad del feto a los distintos procesos patológicos y a algunos medios empleados para el diagnóstico y el tratamiento, hacen necesario el conocimiento todos estos aspectos y la aplicación de protocolos basados en la mejor evidencia disponible.

Se presentan, clasificadas por sistemas, las patologías que con mayor frecuencia constituyen un motivo de consulta en el Servicio de Urgencias, y la conducta que se considera más adecuada atendiendo a la gravedad de los procesos y los medios disponibles para la correcta actuación.

\section{TRANSTORNOS RESPIRATORIOS}

El embarazo produce una serie de modificaciones fisiológicas en el aparato respiratorio de las gestantes que deben conocerse para identificarlos como patológicos o no por los síntomas que ocasionan. Se pueden resumir en: congestión nasofaríngea por aumento de flujo sanguíneo (a veces con epistaxis), elevación del diafragma y aumento del diámetro torácico, hiperventilación relativa (de origen central mediada por la progesterona) con elevación de la $\mathrm{PO}_{2}(106-108 \mathrm{~mm} \mathrm{Hg})$ y descenso de la $\mathrm{PCO}_{2}(27-34 \mathrm{~mm} \mathrm{Hg})$, cierta alcalosis respiratoria $(\mathrm{pH} 7,47$ y bicarbonato sérico $18-21 \mathrm{mEq} / \mathrm{L}$ ) y aumento del volumen tidal. La frecuencia respiratoria y el volumen espiratorio forzado no varían ${ }^{1,2}$.

La embarazada tiene mayor riesgo de desarrollar edema agudo de pulmón como complicación de diversas enfermedades (debido a la hipoalbuminemia relativa y a una mayor susceptibilidad del endotelio alveolar y capilar a las endotoxinas y otros agentes).

Además, los procesos respiratorios aumentan el riesgo de parto pretérmino y el feto tolera mal las situaciones de hipoxia y acidosis, por lo que éstas deben ser evitadas o tratadas de forma "agresiva" en la madre.

\section{Disnea}

La evaluación de la disnea en la gestante presenta la dificultad de diferenciar la hiperventilación fisiológica inducida por progesterona de la disnea como síntoma de una enfermedad subyacente, siendo las más frecuentes: de origen respiratorio (asma o tromboembolismo pulmonar), cardiaco o por anemia grave. Para el diagnóstico diferencial conviene tener en cuenta los siguientes parámetros:

- Antecedentes médicos personales.

- Comienzo súbito: orienta hacia el diagnóstico de embolismo pulmonar.

- Asociación de otros síntomas: tos, dolor torácico, hemoptisis, limitación considerable de la actividad física, ortopnea progresiva, taquipnea que nunca son fisiológicos.

Una vez descartado que se trate de un síntoma propio del embarazo o si existen dudas, se recomienda la realización de pruebas complementarias: gasometría arterial, espirometría, radiografía simple de tórax y, si es necesario, escáner torácico con radionúclidos ${ }^{3}$.

\section{Infecciones}

\section{Infección de vías altas}

Las infecciones de vías altas contituyen procesos autolimitados y los tratamientos disponibles son de escasa eficacia demostrada, por lo que deben administrarse aquellos con evidencia de inocuidad para el feto. Para alivio de los síntomas se recomienda: inhalación de aire caliente humidificado para la congestión y acetaminofeno para la odinofagia, cefalea y fiebre.

En la mayoría de los casos los antibióticos no están indicados (se debe seguir el mismo criterio que en pacientes no gestantes). Los antitusígenos y descongestionantes, dado que no han demostrado un beneficio significativo no se consideran de elección. Si se desea tratar la rinorrea pueden utilizarse sprays nasales con bromuro de ipratropio o de cromolina sódica que pertenecen a la categoría $B$ en el embarazo $^{4}$ (Tabla 1).

La mayoría de los antiinflamatorios no esteroideos (AINE) pertenecen a la categoría $B$ en el primer trimestre y $D$ en el segundo y tercero. Los antihistamínicos a la categoría B y C y la codeína a la C (Tabla 1). 
Tabla 1. Clasificación de los fármacos en el embarazo según la FDA (Food and Drug Administration).

\begin{tabular}{|c|c|c|c|}
\hline Categoría & Estudios en animales & Estudios en humanos & $\begin{array}{c}\text { Posible beneficio } \\
\text { mayor a riesgo }\end{array}$ \\
\hline $\mathbf{A}$ & No demostrada teratogenicidad & No demostrada teratogenicidad & Sí. Probablemente seguros \\
\hline \multirow{2}{*}{ B } & No demostrada teratogenicidad & No realizados & \multirow{2}{*}{$\begin{array}{l}\text { Sí. No existen pruebas de riesgo } \\
\text { en humano }\end{array}$} \\
\hline & Teratogenicidad demostrada & No demostrada teratogenicidad & \\
\hline \multirow{2}{*}{ C } & Teratogenicidad demostrada & No realizados & \multirow{2}{*}{$\begin{array}{l}\text { Sí, aunque no se puede } \\
\text { descartar la existencia de } \\
\text { riesgo. }\end{array}$} \\
\hline & No realizados & No realizados & \\
\hline D & $\begin{array}{c}\text { Teratogenicidad demostrada } \\
\text { o no }\end{array}$ & Teratogenicidad demostrada* & $\begin{array}{c}\text { Sí, aunque existen pruebas de } \\
\text { riesgo }\end{array}$ \\
\hline $\mathbf{X}$ & Teratogenicidad demostrada & Teratogenicidad demostrada* & $\begin{array}{c}\text { No. Nunca administrar en el } \\
\text { embarazo }\end{array}$ \\
\hline
\end{tabular}

* En estudios o en informes publicados tras la administración del producto.

\section{Sinusitis}

Es preciso confirmar la existencia de rinorrea y obstrucción al flujo nasal significativa durante más de 7 días junto con dolor a la presión de senos y fiebre. Tratamiento de elección: amoxicilina-clavulánico $(1 \mathrm{~g} / 8 \mathrm{~h})$ o cefuroxima axetilo. Contraindicados: quinolonas y tetraciclinas.

Como coadyuvantes pueden administrarse sprays nasales salinos o pseudoefedrina (categoría C, contraindicada en primer trimestre y en hipertensas) o sprays de esteroides (budesonida o beclometasona).

\section{Bronquitis}

La bronquitis puede ser clínicamente similar a la neumonía, diferenciándose de ésta por la ausencia de anomalías en la radografía de tórax. Se trata de un proceso autolimitado y de etiología vírica en el $90 \%$ de los casos, por lo que no está indicada en general la prescripción de antibióticos. Tratamiento sintomático, similar al de la infección de vías altas.

\section{Gripe}

Se recomienda la vacunación universal de las embarazadas contra el virus de la gripe (American college of obstetricians and gynecologists (ACOG) y Centers for disease control and prevention $(C D C)$ ). La mujer gestante con gripe tiene mayor riesgo de desarrollar complicaciones graves y requerir hospitalización. Existen datos contradictorios acerca de la posible teratogenicidad del virus de la gripe.

En cuanto al tratamiento, se recomienda reposo, hidratación y acetaminofeno, así como vigilancia estricta de los síntomas y, ante la aparición de disnea, signos de hipoxia o anomalías en el estudio radiológico, considerar el ingreso hospitalario.

\section{Neumonía}

La neumonía presenta en gestantes una incidencia similar a la población general, aunque puede aumentar la morbilidad materna y fetal (edema pulmonar y parto pretérmino).

Clínica: escalofríos súbitos seguidos de fiebre, dolor torácico de tipo pleurítico, tos productiva purulenta y auscultación de crepitantes.

El diagnóstico se confirma mediante la realización de una radiografía simple de tórax. La indicación de estudio radiológico es la misma independientemente del estado de embarazo. En algunos casos puede ser necesaria la obtención de gasometría sanguínea, hemocultivos o cultivos de esputo. Debe realizarse control de bienestar fetal.

El tratamiento pautado en la neumonía adquirida en la comunidad se basa en: eritromicina, azytromicina o ceftriaxona y, como antipirético, acetaminofeno. Otros antibióticos que pueden administrarse son: 
otros beta-lactámicos, clindamicina o aminoglucósidos. Están contraindicados: doxiciclina, claritromicina (clasificada en la categoría C, a pesar de ser macrólido no está establecida su inocuidad en el embarazo) y quinolonas.

Ante el riesgo de edema pulmonar y de parto pretérmino, es preciso considerar el ingreso hospitalario en algunos casos y, si la gestante va a realizar reposo prolongado, administrar profilaxis para enfermedad tromboembólica. Si desciende la saturación de oxígeno por debajo de $90-95 \%$, debe suplementarse (para un adecuado aporte de oxígeno al feto, la saturación materna debería estar por encima del $95 \%$ y la $\mathrm{PO}_{2}$ por encima de $70 \mathrm{~mm}$ de $\mathrm{Hg}$ ).

El tratamiento de la neumonía adquirida en el hospital abarca: antibióticos de amplio espectro (amoxicilina, cefalosporinas, eritromicina), dependiendo de los resultados del estudio microbiológico. La dosis de amoxicilina y de ampicilina debe doblarse en el embarazo debido a que se produce un mayor aclaramiento renal ${ }^{4,5}$.

\section{Asma}

La hiperreactividad de la vía aérea disminuye durante el embarazo en la mayoría de las pacientes asmáticas. Teniendo en cuenta las modificaciones fisiológicas del equilibrio ácido-base en la gestante y su menor capacidad de compensación de la acidosis, una $\mathrm{PaCO}_{2}$ superior a $35 \mathrm{~mm} \mathrm{Hg}$, $\mathrm{pH}$ inferior a 7,35 y descenso de la $\mathrm{PaO}_{2}$ constituyen un mayor compromiso respiratorio en la embarazada con asma respecto a la no gestante.

Las exacerbaciones del asma en el embarazo, que ocurren en un 20-36\% de las pacientes, pueden producir hipoxia fetal, así como la disminución crónica de la función pulmonar si estas pacientes no reciben un tratamiento adecuado ${ }^{6}$. El tratamiento debe seguirse según los mismos principios que si no existe embarazo.

\section{Asma crónico}

Para el asma moderado persistente se recomiendan corticoides inhalados a dosis intermedia (preferentemente budesonida, con la que existe mayor experiencia, pero pueden ser otros si la gestante estaba bien controlada con ellos antes del embarazo) o una combinación de corticoides a baja dosis con un beta-adrenérgico de larga duración (de elección salmeterol). Como beta-adrenérgico de acción rápida se considera de elección el albuterol o salbutamol.

\section{Crisis asmática}

Se considera crisis asmática el empeoramiento progresivo y en tiempo breve de todos o alguno de los síntomas que definen al asma (crisis de tos, sibilancias y disnea). Requiere monitorización intensiva materna $\mathrm{y}$ fetal.

Se debe administrar oxigenoterapia (inicialmente a $3-4 \mathrm{l} / \mathrm{min}$ ) ajustando la $\mathrm{FiO}_{2}$ (28-30\%) para mantener una $\mathrm{pO}_{2}$ adecuada (al menos $70 \mathrm{~mm} \mathrm{Hg}$ o pulsioximetría de al menos 95\%), fluidoterapia con sueros que contengan glucosa (salvo pacientes hiperglucémicas) a $100 \mathrm{ml} / \mathrm{h}$ (precaución para no provocar sobrehidratación). Se recomienda reposo en posición semi-sentada.

La farmacoterapia indicada la constituyen:

- Beta2-adrenérgico: salbutamol nebulizado (0,5-1 cc diluido en 3-5 cc de suero salino cada 30 minutos hasta estabilizar a la paciente o un máximo de $2-3$ veces).

- Corticoides: hidrocortisona (2 mg/Kg IV en bolo cada 4 horas) o metilprednisolona (60-125 $\mathrm{mg}$ en bolo IV cada 6 horas).

- Metilxantinas: aminofilina IV. En general no se recomienda su uso en la crisis en el embarazo porque no ha demostrado mayor beneficio que la sola administración de los corticoides y los beta-adrenérgicos y aumenta los efectos adversos de éstos.

- Anticolinérgicos: en crisis graves. Bromuro de ipratropio (250-500 $\mu \mathrm{g}$ nebulizado), que se puede asociar al betaadrenérgico o después de él.

Si existe amenaza de parto pretérmino, el fármaco de elección es el atosiban y, de segunda elección el nifedipino (no conviene asociar dos beta-adrenérgicos, ni la administración de indometacina). 
Si el desencadenante de la crisis asmática ha sido una infección respiratoria, ésta será en la mayoría de los casos de origen vírico, pero si se sospechase una infección bacteriana, debe instaurarse inmediatamente tratamiento antibiótico con cefuroxima endovenosa y, si la sospecha etiológica orienta hacia Mycoplasma pneumoniae, Chlamydia pneumoniae o Legionella, debe administrarse eritromicina ${ }^{7-9}$.

En el parto de la paciente asmática se puede emplear oxitocina y prostaglandina $\mathrm{E}_{2}$. Están contraindicados la prostaglandina $\mathrm{F}_{2 \alpha}$ y los ergotínicos (efecto broncoconstrictor). La analgesia epidural puede estar recomendada porque reduce el consumo de oxígeno; deben evitarse los morfínicos.

\section{Tromboembolismo pulmonar (TEP)}

El embarazo y el puerperio aumentan el riesgo de tromboembolismo venoso. La incidencia de TEP es de 1-3/1.000 embarazos. La mortalidad de este proceso es de un $30 \%$, si bien con un diagnóstico y tratamiento precoces disminuye a un $2-8 \%$.

Clínica: puede presentarte desde oligosintomático (inquietud, ansiedad) hasta un cuadro de shock en caso de TEP masivo (con fallo cardiaco derecho y alto riesgo de muerte en las 2 primeras horas). No obstante, los signos y síntomas más frecuentes son disnea (generalmente de aparición aguda), taquipnea, taquicardia, dolor pleurítico y tos seca, con o sin clínica de trombosis venosa profunda de extremidades inferiores. Otros síntomas que pueden aparecer son: hemoptisis, ortopnea, fiebre, cianosis, sudoración. La auscultación puede mostrar aumento del $2^{\circ}$ tono, estertores y crepitantes.

Diagnóstico: dado que la presentación es muy variable y a menudo inespecífica, la clínica es insuficiente para el diagnóstico y es necesario realizar estudios complementarios:

\section{Laboratorio:}

- Gasometría arterial: no es sensible ni específica. La alcalosis respiratoria es un hallazgo característico tanto del embarazo normal como en el TEP. Con frecuencia en el TEP existe normalidad en la $\mathrm{PO}_{2}, \mathrm{PCO}_{2}$ y diferencia alveoloarterial.
- Dímero-D > 500 ng/ml: ofrece alta sensibilidad pero baja especificidad, con un elevado valor predictivo negativo fuera del embarazo. Sin embargo, en la gestación existe una elevación fisiológica del Dímero-D en incremento conforme avanza la edad gestacional, con pico en el momento del parto y en el puerperio precoz. Algunos estudios también han demostrado normalidad en el Dímero-D en embarazadas con diagnóstico de TEP. Por tanto, esta prueba tiene también poca utilidad en la gestante.

- Es conveniente tener un estudio de hemograma, electrolitos, pruebas de coagulación y bioquímica hepática y renal antes de instaurar el tratamiento anticoagulante.

Radiológicos:

- Radiografía simple de tórax para excluir proceso infeccioso o neumotórax.

- Ecografía-Doppler de extremidades inferiores. Dado que el tratamiento de la trombosis venosa profunda y del TEP no masivo es el mismo, el estudio radiológico puede comenzarse con ecografía-Doppler de extremidades inferiores y, según algunos autores, si se documenta la presencia de trombo se instaura el tratamiento sin necesidad de más estudio. Sin embargo, si el Doppler es negativo ( $30 \%$ de los casos de TEP), deben realizarse otras pruebas ${ }^{10}$.

- La mayoría de los autores recomiendan realizar siempre además del Doppler (sea positivo o negativo) un estudio de perfusión pulmonar (que si es normal descarta un TEP) y si está alterado, una gammagrafía de ventilación/pefusión. Otros consideran como test diagnóstico de elección en el embarazo el angio-TAC ${ }^{10}$.

Tratamiento:

- El tratamiento puede iniciarse ante una alta sospecha clínica y mantenerse si el estudio informa de alta o media probabilidad de TEP o bien iniciarse tras este diagnóstico radiológico.

- Cuando el informe indica una baja probabilidad y el Doppler de extremidades es positivo, el tratamiento debe realizarse igualmente. 
- Si el informe es de baja probabilidad de TEP y el Doppler es negativo pero la sospecha clínica es alta, debe instaurarse tratamiento y repetir Doppler y gammagrafía en una semana.

- Si la probabilidad clínica es alta, con gammagrafía de baja probabilidad o de calidad insuficiente para diagnóstico y Doppler negativo, puede considerarse la realización de angiografía pulmonar, resonancia magnética, o, si la paciente se halla en el puerperio, TAC helicoidal (prueba de elección en no gestantes) (Fig. 1) ${ }^{11}$.

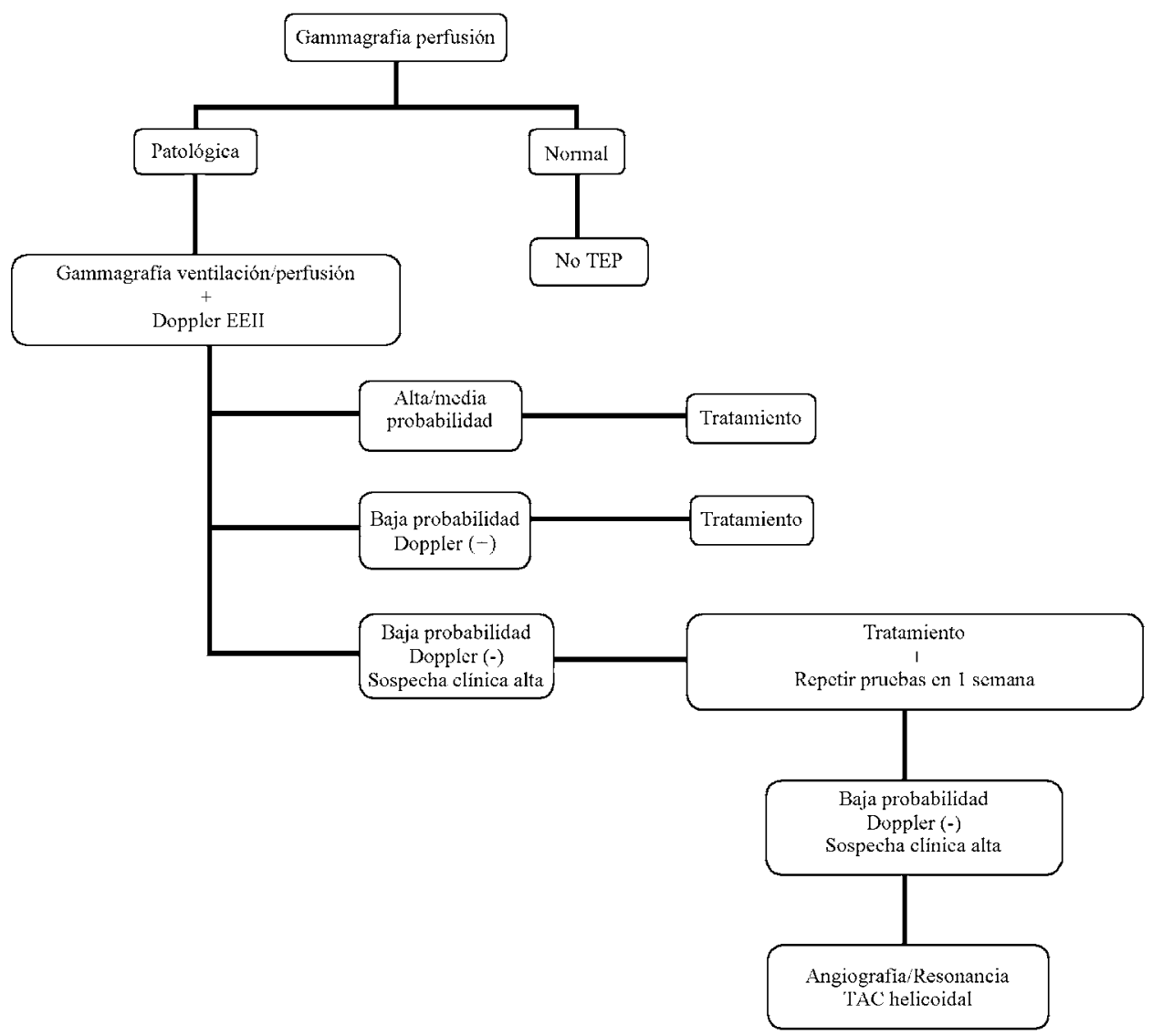

Figura 1. Algoritmo diagnóstico en gestantes con sospecha de TEP.

Pauta:

- Estabilización de la paciente y administración de oxígeno si existe hipoxemia (si hay compromiso hemodinámico y/o fallo respiratorio, ingreso en Unidad de Cuidados Intensivos).

- Terapia anticoagulante: de elección heparina de bajo peso molecular (HBPM) (en TEP masivo, heparina no fraccionada (HNF)), con dosis inicial en función del peso al inicio del embarazo. Duración: todo el embarazo y al menos las seis semanas del puerperio (en total un mínimo de 3 meses). En el puerperio, desde el $2^{\circ}$ ó $3^{\circ}$ día la heparina puede ser sustituida por anticoagulantes orales: enoxaparina (HBMP): $1 \mathrm{mg} / \mathrm{Kg} / 12 \mathrm{~h}$; dalteparina (HBMP): 100 
$\mathrm{U} / \mathrm{Kg} / 12 \mathrm{~h}$; tinzaparina (HBMP): $175 \mathrm{U} /$ Kg; HNF: 5.000 UI iniciales y continuar con perfusión de 1000-2000 UI/h, control de TTPa o de anti-factor Xa a las $6 \mathrm{~h}$ y luego al menos 1 vez al día si se emplea esta heparina.

\section{TRANSTORNOS UROLÓGICOS}

Los cambios fisiológicos del tracto urinario en la gestación favorecen la aparición de patología que constituye motivo frecuente de consulta en urgencias

\section{Infecciones}

La bacteriuria asintomática $(>100.000$ Unidades Formadoras de Colonias (UFC)/ ml en 2 muestras obtenidas por micción o la presencia de más de 1.000 en una muestra de orina recogida por sondaje, en ausencia de síntomas), debe detectarse y tratarse en la gestante para disminuir el riesgo de infección urinaria sintomática y los riesgos de prematuridad y bajo peso asociados a esta patología.

\section{Cistitis aguda}

La cistitis aguda presenta una clínica de polaquiuria (puede ser fisiológica), disuria, tenesmo vesical. Ocasionalmente hematuria.

El diagnóstico se hace mediante el estudio del sedimento de orina y urocultivo (se considera positivo con $>100 \mathrm{UFC} / \mathrm{ml}$ en presencia de síntomas y piuria).

En el tratamiento no hay evidencia para recomendar uno u otro esquema terapéutico (Tabla 2) ${ }^{12,13}$. En infecciones recurrentes se debe considerar la profilaxis durante todo el embarazo. Pautas: nitrofurantoína, $50-100 \mathrm{mg} /$ día, o cefalexina, $250-500 \mathrm{mg} /$ día. Conviene realizar urocultivo de control 1 ó 2 semanas tras finalizar el tratamiento.

Tabla 2. Pautas de antibioterapia para la cistitis aguda y la bacteriuria asintomática.

\begin{tabular}{llc}
\multicolumn{1}{c}{ Antibiótico } & \multicolumn{1}{c}{ Dosis } & Días \\
\hline Fosfomicina & $3 \mathrm{~g} / \mathrm{d}$ & 1 ó 2 \\
Amoxicilina & $250 \mathrm{mg} / 8 \mathrm{~h} \mathrm{ó} 500 \mathrm{mg} / 8-12 \mathrm{~h}$ & $3-7$ \\
Amoxicilina-clavulánico & $250 \mathrm{mg} / 8 \mathrm{~h} \mathrm{ó} 500 \mathrm{mg} / 8-12 \mathrm{~h}$ & $3-7$ \\
Nitrofurantoína & $100 \mathrm{mg} / 12 \mathrm{~h}$ & $3-7$ \\
Cefalexina & $250 \mathrm{mg} / 6 \mathrm{~h} \mathrm{ó} 500 \mathrm{mg} / 12 \mathrm{~h}$ & $3-7$ \\
Cefadroxilo & $500 \mathrm{mg} / 12 \mathrm{~h}$ & $3-7$ \\
Cefuroxima & $250 \mathrm{mg} / 12 \mathrm{~h}$ & 3 \\
Cefixima & $400 \mathrm{mg} / \mathrm{d}$ & 3 \\
Cefpodoxima & $100 \mathrm{mg} / 12 \mathrm{~h}$ & 3 \\
\hline
\end{tabular}

\section{Pielonefritis aguda}

- Clínica: dolor lumbar o en el flanco, fiebre $\left(>38^{\circ} \mathrm{C}\right)$, naúseas con o sin vómitos, a veces hipersensibilidad en ángulo costo-vertebral. Los síntomas miccionales pueden estar o no presentes. La gestante con pielonefritis es más susceptible de desarrollar complicaciones como anemia, bacteriemia, síndrome de distrés respiratorio del adulto, sepsis e insuficiencia renal.
- Diagnóstico diferencial: colecistitis, apendicitis, corioamnionitis, degeneración o necrosis de mioma, rotura o torsión de quiste ovárico, trabajo de parto.

- Diagnóstico: por la clínica. Se recomienda la obtención de urocultivo y, en algunos casos (signos de sepsis o enfermedades concomitantes como la diabetes) hemocultivos. Si tras 24-48 horas de tratamiento persiste la fiebre o los síntomas debe repetirse el 
urocultivo y realizarse pruebas de imagen del tracto urinario.

- Tratamiento: en general se recomienda hospitalización y antibioterapia endovenosa, al menos hasta que la paciente esté apirética y con clara mejoría clínica durante $24-48 \mathrm{~h}(\text { Tabla } 3)^{13}$. Posteriormente puede continuarse el mismo tratamiento por vía oral hasta completar $10-14$ días $^{12,13}$. Para las recurrencias (6-8\%), pauta igual que en las cistitis recurrentes. El tratamiento ambulatorio se puede considerar en casos seleccionados, comenzando con ceftriaxona IM (1-2 g) y observación de la paciente al menos unas horas.

Tabla 3. Pautas de antibioterapia para la pielonefritis aguda.

\begin{tabular}{ll}
\hline \multicolumn{2}{c}{ Primera elección } \\
\hline Amoxicilina-clavulánico & $1 \mathrm{~g} / 8 \mathrm{~h} \mathrm{IV}$ \\
Cefuroxima axetilo & $750 \mathrm{mg} / 8 \mathrm{~h} \mathrm{IV}$ \\
Ceftriaxona* $^{*}$ & $1 \mathrm{~g} / 24 \mathrm{~h} \mathrm{IM}$ ó IV \\
\hline
\end{tabular}

\begin{tabular}{ll}
\hline \multicolumn{2}{c}{ Segunda elección y/o alergia a beta-lactámicos } \\
\hline Aztreonam & $1 \mathrm{~g} / 8 \mathrm{~h} \mathrm{IV}$ \\
Fosfomicina & $100 \mathrm{mg} / \mathrm{kg} / \mathrm{d}$ \\
Gentamicina ó & $3 \mathrm{mg} / \mathrm{Kg} / \mathrm{d} \mathrm{IM}$ ó IV \\
Tobramicina & \\
\hline
\end{tabular}

${ }^{*}$ A las 48 h, si existe apirexia, pasar a cefixima $400 \mathrm{mg} / \mathrm{d}$ oral.

\section{Uropatía obstructiva}

La uropatía obstructiva aguda es más frecuente en $2^{\circ}$ y $3^{\text {er }}$ trimestres, aunque existe una hidronefrosis fisiológica presente ya desde la $6^{\circ}-10^{\circ}$ semanas de embarazo.

\section{Cólico nefrítico}

Generalmente (aunque no siempre) está provocado por litiasis. El diagnóstico es clínico: dolor en fosa lumbar/flanco irradiado a región inguinal. Se puede acompañar de síndrome miccional, náuseas y vómitos y hematuria macro o microscópica.

Si tras $48 \mathrm{~h}$ de tratamiento persisten los síntomas está indicado realizar ecografía renal, que aporta información sobre la dila- tación de la vía urinaria (no olvidando diferenciar la dilatación fisiológica de la hidronefrosis por obstrucción) y la presencia de cálculos. Si existe cálculo a nivel de uréter distal rara vez se diagnostica por ecografía. La eco-Doppler renal (estudio de índices de resistencia intrarrenal y flujo ureteral), en exploradores con experiencia, puede servir para diferenciar la obstrucción de la ectasia no obstructiva.

Se debe hacer diagnóstico diferencial con otros cuadros de dolor abdominal, obstétricos o no: parto, desprendimiento de placenta, embarazo ectópico (en $1^{\circ}$ trimestre), apendicitis, diverticulitis, colecistitis, pielonefritis,...

Otras pruebas a realizar son: hemograma, bioquímica y sedimento: Pueden orientar hacia otras causas de dolor abdominal. En los infrecuentes casos de evolución tórpida puede estar justificada la realización de técnicas radiológicas con contraste modificadas (una sola placa tras la administración de contraste) o resonancia magnética.

El tratamiento adecuado son: medidas conservadoras con hidratación y analgésicos, que resuelven hasta un $90 \%$ de los casos. Si el cuadro persiste o empeora en 48-72 horas pueden estar indicados tratamientos invasivos (derivación urinaria mediante cateterización ureteral con "doble J" o nefrostomía percutánea) (Tabla 4) ${ }^{13}$.

Tabla 4. Indicaciones de derivación urinaria.

\section{INFECCIONES}

La importancia de las infecciones en el embarazo viene dada por el hecho de que algunos patógenos pueden provocar infecciones congénitas o teratogénesis en el feto y/o actuar con especial virulencia en la embarazada. Además, la hipertermia y la fiebre en el primer trimestre aumentan el riesgo de aborto y de defectos congénitos ${ }^{14}$. 
Por otra parte, en la asistencia de urgencia no existe posibilidad de realizar un diagnóstico de certeza en la mayoría de los procesos infecciosos con riesgo de transmisión vertical. La valoración inicial en urgencias ante un proceso febril en la embarazada debe ser similar a la realizada en la no gestante.

Las bases para llegar a un diagnóstico de sospecha y la actitud terapéutica adecuada son: anamnesis, exploración física general y gineco-obstétrica y pruebas complementarias dirigidas según lo anterior (Tabla 5) ${ }^{15}$.
En general, si la paciente no reúne criterios de gravedad (hipotensión, taquicardia, taquipnea, enfermedades crónicas previas, alteraciones analíticas graves...), y no hay signos de compromiso fetal no se precisa ingreso hospitalario (a excepción de algunas enfermedades exantemáticas como la varicela con erupción florida, aunque no existe consenso al respecto). El tratamiento consiste en antitérmicos y, si se sospecha infección bacteriana, con focalidad, antibiótico. El estudio serológico y de seguimiento deberá realizarse de forma ambulatoria.

Tabla 5. Pauta inicial en la gestante con fiebre.

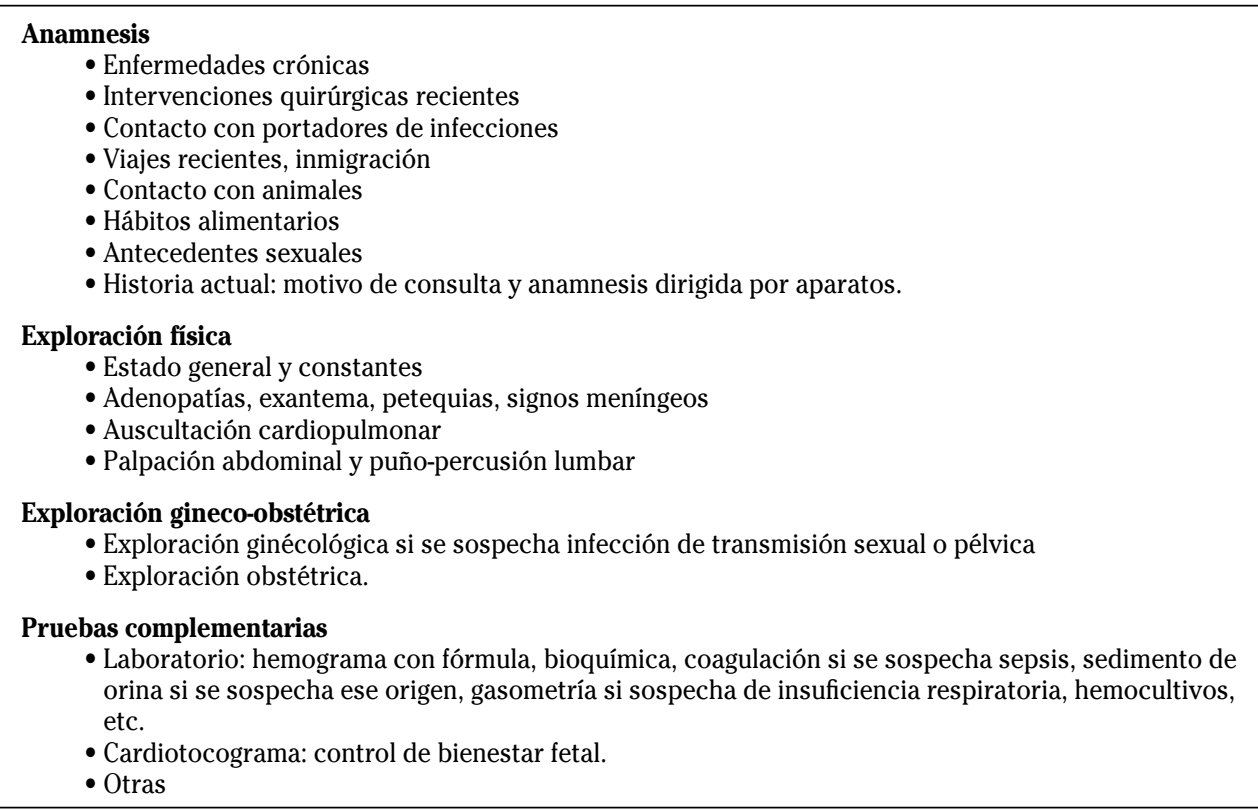

\section{Infecciones TORCH}

Este acrónimo incluye las infecciones de riesgo de transmisión vertical: Toxoplasma, Rubeola, Citomegalovirus (CMV), Virus del Herpes Simple (VHS) y otros: Varicela zoster, Parvovirus B19, enterovirus (Coxackie, Echo, Polio), Treponema pallidum, Listeria monocytogenes, etc.

El diagnóstico de estas infecciones en la práctica en urgencias, se basa en la clínica y la anamnesis (cuando hay una posible ex- posición reconocida a un agente), puesto que la confirmación microbiológica o serológica no se puede obtener en un primer momento.

Las infecciones de este grupo más frecuentes en la consulta de urgencias y que además puedan requerir la toma de decisiones inmediatas en su manejo, podrían ser las siguientes infecciones víricas: varicela, herpes genital, condiloma e infección por VIH. 


\section{Varicela}

La varicela es una enfermedad producida por virus Varicela-zóster. El 85-95\% de los adultos son inmunes. La transmisión tiene lugar por vía respiratoria (desde 2 días antes de la aparición del exantema) y por lesiones cutáneas hasta estar en fase de costra. Puede darse transmisión vertical $<1 \%$ en $1^{\circ}$ trimestre, $2 \%$ en $2^{\circ}$ y $>50 \%$ a partir de semana 36 , sobre todo en los días cercanos al parto.

El cuadro clínico se presenta con: fiebre, malestar general y exantema pruriginoso (pápulas vesículas y costras en diferentes estadios) que se inicia en cabeza y se extiende hacia tronco y extremidades). Existe riesgo de complicaciones como la neumonía varicelosa (20-25\% en adultos), que en la gestante es más grave. Aparece a los 3-5 días del exantema (tos, disnea, fiebre, infiltrados nodulares en la radiografía de tórax) y conlleva una mortalidad materna del $15-40 \%$ sin tratamiento. Parecer existir más riesgo de neumonía en pacientes con exantema muy extenso ( $>100$ lesiones).

El diagnóstico de varicela es inicialmente clínico, con confirmación serológica posterior. En ausencia de complicaciones la conducta a seguir es tratamiento sintomático en domicilio. El aciclovir no se recomienda de forma rutinaria, puesto que no ha demostrado beneficio claro sobre el riesgo de complicaciones en el adulto inmunocompetente. Si la paciente presenta disnea, taquipnea y tos debe realizarse radiografía de tórax. En caso de neumonía, el empleo de aciclovir ev disminuye la mortalidad. Se recomienda ingreso y tratamiento en este caso y puede estar indicado también en pacientes con erupción muy extensa. La pauta adecuada es: $5-10 \mathrm{mg} / \mathrm{kg} / 8 \mathrm{~h}$ durante 7 días. Algunos recomiendan asociar ampicilina ev/4 h.

Si la varicela se contrae a término o preparto, debe intentar retrasarse el parto al menos 5-7 días desde la aparición del exantema para permitir la inmunización pasiva del feto.

Ante gestantes asintomáticas que consultan por exposición a virus Varicela-zoster, primero debe conocerse su estado de inmunidad. Las gestantes inmunes no están en riesgo. En pacientes seronegativas y si la exposición ha sido significativa está indicada la administración lo más precoz posible de gamma-globulina hiperinmune anti-varicela zoster (VZIG) (puede ser eficaz hasta 4 días después del contacto) a una dosis IM de 625 U. No parece prevenir el riesgo de transmisión vertical pero sí la aparición de complicaciones maternas. En enero de 2006 la FDA emitió un comunicado informando de la suspensión temporal en la producción de VZIG, por lo que ha habido problemas de abastecimiento.

\section{Herpes genital simple}

El herpes genital simple está causado generalmente por virus Herpes simplex tipo II, aunque también puede ser por Herpes simplex tipo I. Existe riesgo de transmisión vertical por vía transplacentaria (5\%), sobre todo en la primoinfección, pero fundamentalmente en el momento del parto (90-95\%), bien por vía ascendente si existe rotura de membranas o bien por el paso del feto a través del canal del parto, con alto riesgo de infección grave y mortalidad. La co-infección por VIH aumenta los riesgos de transmisión perinatal de ambos virus.

- Clínica: en la infección primaria, hasta un $70 \%$ de las pacientes pueden ser asintomáticas ${ }^{16}$. Otras veces comienza con parestesias, prurito, escozor o quemazón, edema y eritema, con o sin síndrome general, que precede unos 2 días a la aparición de lesiones papulovesiculosas muy dolorosas en la región vulvoperineal e incluso en cérvix. Pueden aparecer adenopatías dolorosas, disuria y exudado uretral. El episodio suele durar unas 3 semanas. Las recurrencias se caracterizan por la aparición de las lesiones vesiculares, generalmente en la misma localización que en la primoinfección, pero con síntomas de menor duración e intensidad.

- Diagnóstico: clínico, con toma de exudado de las lesiones para cultivo del virus o PCR y confirmación posterior. El estudio serológico puede servir para determinar si la infección es primaria o recurrente (por coincidencia o no con el tipo obtenido en el cultivo), si bien no es posible realizarlo urgente. 
La conducta a seguir difiere según la situación:

- En la primoinfección: si la clínica y la exploración es sugestiva, se debe pautar tratamiento con aciclovir oral (o endovenoso si se sospecha infección diseminada). Pauta: $200 \mathrm{mg} / 5 \mathrm{~h}$ ó $400 \mathrm{mg} / 8 \mathrm{~h}$ durante 5-10 días. Este fármaco no ha demostrado teratogenicidad en ningún caso pero el número de casos en que se ha evaluado es insuficiente como para establecer conclusiones definitivas por lo que antes de la semana 20 se recomienda emplearlo de forma limitada. El tratamiento reduce la intensidad y duración de los síntomas ${ }^{17}$. Famciclovir y valaciclovir se consideran también seguros.

- Si el episodio de primoinfección coincide con el parto, se recomienda cesárea urgente y si aparece en las 6 semanas previas a la fecha probable de parto, se recomienda programar cesárea.

- Si se trata de un episodio recurrente se puede pautar aciclovir oral para reducir la clínica y la eliminación viral si se instaura en las primeras 24 horas desde la aparición de las lesiones, si bien no todos los estudios de evidencia lo recomiendan ${ }^{20,18}$.

- Si el episodio aparece en el parto o existen síntomas de escozor-dolor vulvar con historia de herpes aun en ausencia de lesiones evidentes, debe realizarse cesárea ${ }^{20,19}$, aunque algunos no lo recomiendan ${ }^{21}$.

- Si en el momento del parto no existen lesiones ni síntomas, aunque haya existido durante el embarazo recurrencia, no está indicada la cesárea rutinaria. No obstante, debe evitarse la monitorización fetal interna.

- En las gestantes que han presentado al menos un episodio de recurrencia durante el embarazo se recomienda administrar aciclovir $400 \mathrm{mg} / 8 \mathrm{~h}$ desde la semana 36 hasta el parto para disminuir el riesgo de recurrencias en el periodo cercano al parto y la diseminación del virus, aunque no hay datos acerca de su influencia en la transmisión vertical.
- Si existe rotura espontánea de membranas y episodio de herpes y el embarazo está a término debe practicarse cesárea urgente. En gestaciones pretérmino, conducta expectante (al menos hasta la semana 32-34) con maduración pulmonar con corticoides y profilaxis antibiótica. La administración de aciclovir puede disminuir la intensidad y duración de los síntomas y lesiones, pero no parece claro que disminuya el riesgo de transmisión vertical, por lo que puede emplearse o no.

\section{Condiloma o verrugas genitales por HPV}

En la $2^{\text {a }}$ década de la vida se estima una prevalencia de HPV del 20-25\% (mayor en determinados grupos de riesgo), y a partir de los 35 años, alrededor del 5\%. Las embarazadas con historia de condilomas genitales tienen un riesgo de 7/1.000 partos de que el hijo pueda desarrollar papilomatosis de las vías respiratorias por transmisión vertical. Los partos prolongados más de 10 horas duplican este riesgo. Sin embargo, los partos por cesárea no lo disminuyen. Se desconoce la eficacia del tratamiento de los condilomas en la prevención de la transmisión vertical de la infección ${ }^{20}$.

\section{Infección por VIH}

En ausencia de terapia y profilaxis materna, la transmisión vertical de la infección por $\mathrm{VIH}^{21}$ es de un 14-25\% (transplacentaria $25-40 \%$ de los casos y en el canal del parto $60-75 \%$ de los casos). Es mayor en coinfectadas con virus de hepatitis C. La lactancia materna aumenta el riesgo en un 15\% en los casos de infección establecida y en un $29 \%$ en los casos de primoinfección. En ausencia de tratamiento profiláctico de transmisión vertical, la cesárea electiva (es decir antes del inicio del trabajo de parto) ejerce un efecto protector para el feto, disminuyendo a la mitad el riesgo de transmisión. El tratamiento durante el embarazo con terapia de antirretroviral de gran actividad (TARGA), disminuye la transmisión vertical por debajo del 1\%. En este colectivo de pacientes no está tan claro el efecto protector de la cesárea electiva, aunque existe un estudio que concluye que la tasa de transmisión, 
independientemente del tratamiento recibido, se asocia con la carga viral materna y la cesárea electiva reduce la transmisión vertical incluso en mujeres con carga viral indetectable ${ }^{22}$. Sin embargo, la embarazada infectada por el VIH presenta mayor riesgo de complicaciones postcesárea, por lo que se han establecido una serie de recomendaciones en cuanto a la elección de la vía de parto, informando de forma adecuada a la gestante y haciéndola partícipe de las decisiones:

Se permitirá parto vaginal si existe buen control gestacional y cumplimiento del tratamiento antirretroviral combinado y si la viremia es menor de 1.000 copias $/ \mathrm{ml}$.

En estas situaciones se deben mantener las membranas íntegras tanto tiempo como sea posible y evitar las maniobras invasivas durante el parto (monitorización interna, microtoma fetal para $\mathrm{pH}$, parto instrumental, episiotomía).

Si la gestante en trabajo de parto presenta serología desconocida, deben determinarse de urgencia al menos VIH y hepatitis B.

Se indicará una cesárea electiva (planificarla entre la 37-38 semana), en caso de:

- Gestante sin tratamiento antirretroviral o con carga viral desconocida.

- Gestante en monoterapia con zidovudina (ZDV).

- Gestante en tratamiento combinado con viremia $>1.000$ copias $/ \mathrm{ml}$.

- Necesidad de inducción de parto.

- No aceptación de parto vaginal por parte de la paciente. existe:

Se indicará una cesárea intraparto si

- Amniorrexis prolongada (aunque se estima que el riesgo de transmisión vertical ya aumenta si transcurren más de 4 horas con membranas rotas).

- Previsión de parto prolongado.

- Monitorización cardiotocográfica externa patológica (contraindicada la monitorización interna y la microtoma de calota fetal para $\mathrm{pH}$ sanguíneo).

En todos estos supuestos será necesario: ligar el cordón umbilical lo antes posible, lavar al recién nacido inmediata- mente tras el parto e inhibir la lactancia materna.

El tratamiento antirretroviral indicado durante el parto vaginal o la cesárea es:

- No suspender la administración oral de TARGA.

- Añadir ZDV intravenosa durante el parto: $2 \mathrm{mg} / \mathrm{kg} / \mathrm{h}$ durante la $1^{\mathrm{a}}$ hora y continuar con $1 \mathrm{mg} / \mathrm{kg} / \mathrm{h}$ hasta ligar el cordón del recién nacido. En caso de cesárea electiva, comenzar la administración 3 ó 4 horas antes de la intervención.

- En ausencia de tratamiento durante el embarazo efectuar tratamiento intraparto con zidovudina EV + lamivudina $(150 \mathrm{mg} / 12 \mathrm{oral})+$ nevirapina $(200 \mathrm{mg}$ oral, dosis única).

En el puerperio es necesario tratar al recién nacido y reevaluar la necesidad de tratamiento TARGA en la madre.

\section{TRANSTORNOS ENDOCRINOS: DIABETES $^{23}$}

\section{Hipoglucemia}

Si la paciente está consciente se determinará la glucemia capilar ante síntomas como sudoración, palpitaciones, hormigueos, mareo, naúseas.

- Glucemia < $60 \mathrm{mg} / \mathrm{dl}$ : tomar un vaso de leche descremada. $\mathrm{Si}<40 \mathrm{mg} / \mathrm{dl} \mathrm{se}$ añadirán $10 \mathrm{~g}$ azúcar. Repetir si a los 15 minutos persiste glucemia $<60$.

- Glucemia > 60 con síntomas: esperar 5-10 minutos y repetir glucemia. Si no se ha solucionado por efecto "rebote" y la glucemia va en descenso, actuar como en el caso anterior.

Si la paciente está inconsciente se administrará una ampolla de glucagón (1 mg) $\mathrm{SC}$ y, tras la recuperación deberá ingerir un vaso de leche con 4 galletas. Remitir al hospital para valorar cardiotocograma y necesidad de ingreso o no.

Si la paciente está hospitalizada se hará perfusión EV de suero glucosado al 10\% hasta estabilización de la glucemia. Indagar posible causa del episodio y realizar ajustes en la dieta y/o insulinoterapia. 


\section{Cetoacidosis diabética}

Es infrecuente en la embarazada por el estricto control metabólico al que se suelen someter. Puede ser causada por administración de beta-miméticos, corticoides, o por infecciones intercurrentes. Asocia una mortalidad materna del $1 \%$ y elevada mortalidad fetal.

Diagnóstico: se debe sospechar si existen náuseas, vómitos, poliuria, polidipsia, malestar general, disnea, "olor a manzana", glucemia capilar > $300 \mathrm{mg} / \mathrm{dl}$ (aunque puede oscilar desde valores casi normales a otros mucho mayores) y cetonuria. Se confirma por determinación de $\mathrm{pH}<7,30 \mathrm{y}$ bicarbonato $<15 \mathrm{mEq} / \mathrm{l}$.

El tratamiento consiste en:

- Canalizar vía venosa y extraer sangre para analítica (gasometría arterial, glucemia, osmolaridad, cetonemia, bicarbonato, hemograma, ionograma, función renal) y estudio del sedimento de orina con cetonuria y glucosuria.

- Comenzar con $1.000 \mathrm{ml}$ de suero fisiológico $0,9 \%$ en $1^{\text {a }}$ hora y $500-1.000$ $\mathrm{ml}$ (según osmolaridad) de la misma solución en la $2^{\mathrm{a}}$ hora. Continuar con $500 \mathrm{ml} / \mathrm{h}$ con lo mismo o bien con soluciones más hipotónicas (fisiológico $0,45 \%$ si existe hipernatremia o glucosalino). Se puede administrar suero glucosado al $5 \%$ si glucemia $<250 \mathrm{mg} /$ dl. Posteriormente, reposición hídrica oral si la paciente tolera. Hacer control estricto de diuresis.

- Suministrar insulina: disminuir glucemia $75-100 \mathrm{mg} / \mathrm{dl} / \mathrm{h}$. Si la paciente no se ha administrado insulina, se inicia con un bolo de insulina regular EV de 5-10 UI. Si se había administrado insulina previamente no es necesario el bolo y se realiza directamente perfusión de insulina regular EV a $10 \mathrm{UI} / \mathrm{h}$. Control horario de glucemia capilar y si no se objetiva respuesta, doblar la dosis de perfusión. Suspender cuando desaparezca la cetonuria durante 24 h (idóneamente). Dos horas antes de suspender la insulina $\mathrm{EV}$, se inicia la insulina subcutánea.

- Reposición de iones: $\mathrm{Na}$ (con suero fisiológico), $\mathrm{K}$ (no iniciar aporte hasta comprobar normalidad de la diuresis y obtener la determinación de este ión en sangre). Se administra $1 / 4$ como fosfato potásico y $3 / 4$ como cloruro potásico.

- Administrar bicarbonato: sólo indicado si $\mathrm{pH}<7,0$ y bicarbonato $<5 \mathrm{mEq} / \mathrm{l}$ o si acidosis láctica o shock que no responde a fluidoterapia, con $\mathrm{pH}<7,15$ y bicarbonato $<10 \mathrm{mEq} / \mathrm{l}$.

- Monitorización fetal continua si ocurre en el $3^{\circ}$ trimestre. Actitud conservadora hasta estabilizar a la madre. Finalizar gestación si signos de alarma en el registro cardiotocográfico.

\section{BIBLIOGRAFÍA}

1. Funai EF, Gillén-Goldstein J, Roqué H. Changes in the respiratory tract during pregnancy. En: UpToDate, Rose, BD (Ed), UpToDate, Waltham, MA, 2008.

2. Gutiérrez O, SÁnchez-Castaño A. Transtornos pulmonares durante el embarazo. En: Urgencias en Ginecología y Obstetricia: Aproximación a la Medicina basada en la evidencia. Cañete ML, Cabero L. Ed FISCAM, 2007: 243-245.

3. WeInBERger S.E. Disnea during pregnancy. En: UpToDate, Rose, BD (Ed), UpToDate, Waltham, MA, 2008.

4. LARSON L, POWRIE R. Treatment of respiratory infections in pregnant women. En: UpToDate, Rose, BD (Ed), UpToDate, Waltham, MA, 2008.

5. De SwiEt M. Respiratory disorders. En: High Risk Pregnancy Management Options. James DK, Steer PJ., Weiner CP., Gonik B. Ed. W.B. Saunders, 1999: 783-784.

6. Weinberger SE, Shatz M. Physiology and clinical course of asthma in pregnancy. In: UpToDate, Rose, BD (Ed), UpToDate, Waltham, MA, 2008.

7. Shatz M, Weinberger SE. Management of asthma during pregnancy En: UpToDate, Rose, BD (Ed), UpToDate, Waltham, MA, 2008.

8. Lombardía Prieto J, Fernández Pérez M. Patología médica frecuente en el embarazo. En: Ginecología y Obstetricia. Manual de consulta rápida. Ed. TEDEC MEIJI FARMA S.A., 2003: 642-645.

9. Larrañaga C, Roche M, García MA. Asma y embarazo. En: Asistencia a las complicaciones médicas y quirúrgicas del embarazo. Grupo de trabajo sobre asistencia a las complicaciones médicas y quirúrgicas del embarazo de la Sección de Medicina Perinatal de la S.E.G.O. Ed. E. Fabre González. 2007: 261-278. 
10. DaVid R, Schwartz DR, Malhotra A, Weinberger SE. Deep vein thrombosis and pulmonary embolism in pregnancy: Epidemiology, pathogenesis, and diagnosis. En: UpToDate, Rose, BD (Ed), UpToDate, Waltham, MA, 2008.

11. Protocolos S.E.G.O. Complicaciones tromboembólicas de la gestación. 2006.

12. Ноотоn TM, Stamm WE. Urinary tract infections and asymptomatic bacteriuria in pregnancy. En: UpToDate, Rose, BD (Ed), UpToDate, Waltham, MA, 2008.

13. Cañete ML, Buendía E, Del Castillo MC, FernánDEZ Y, BuENdía E. Infección urinaria y uropatía obstructiva en el embarazo. En: Urgencias en Ginecología y Obstetricia: Aproximación a la Medicina basada en la evidencia. Cañete ML, Cabero L. Ed FISCAM, 2007: 339-356.

14. EDWARDS MJ. Review: Hyperthermia and fever during pregnancy. Birth Defects Res A Clin Mol Teratol 2006; 76: 507-516.

15. MuÑoz E, LAÍn N. Infecciones en el embarazo. En: Urgencias en Ginecología y Obstetricia: Aproximación a la Medicina basada en la evidencia. Cañete ML, Cabero L. Ed FISCAM, 2007: 315-326.

16. SÁnchez JM, Sánchez Calvo M. Enfermedades de transmisión sexual y vulvovaginitis. En: Urgencias en Ginecología y Obstetricia: Aproximación a la Medicina basada en la evidencia. Cañete ML, Cabero L. Ed FISCAM, 2007: 588-589.

17. Management of genital herpes in pregnancy. Green-top Guideline №30. September 2007. Royal College of Obstetricians and Gynaecologists.

18. MuÑoz E, LAín N. Infecciones en el embarazo. En: Urgencias en Ginecología y Obstetricia: Aproximación a la Medicina basada en la evidencia. Cañete ML, Cabero L. Ed FISCAM, 2007: 331-332.

19. RILEY LE. Genital herpes simplex virus infection and pregnancy. En: UpToDate, Rose, BD (Ed), UpToDate, Waltham, MA, 2008.

20. Puig-Tintoré LM, Cortés J, Castellsagne X, TorNÉ A, ORdi J, DE José S et al. Prevención del cáncer de cuello uterino ante la vacunación frente al virus del papiloma humano Prog Obstet Ginecol 2006; 49 Supl 2: 5-62.

21. Protocolos SEGO:Infección por VIH y gestación. 2006

22. European Collaborative Study. Mother-tochild Transmission of HIV Infection in the era of Highly Active Antiretroviral Therapy. Clin Infec Dis 2005; 40: 458-465.

23. Lombardía Prieto J, Fernández Pérez M. Patología Obstétrica. En: Ginecología y Obstetricia. Manual de consulta rápida. TEDEC MEIJI FARMA S.A., 2003: 590-592. 